\title{
Investigation of the ultrastructural characteristics of foxtail and broomcorn millet during carbonization and its application in archaeobotany
}

\author{
YANG Qing $^{1,3}$, LI XiaoQiang ${ }^{2 *}$, ZHOU XinYing $^{1,2}$, ZHAO KeLiang $^{1,3}$, JI Ming $^{3,4}$ \& SUN Nan ${ }^{1,3}$ \\ ${ }^{1}$ State Key Laboratory of Loess and Quaternary Geology, Institute of Earth Environment, Chinese Academy of Sciences, Xi'an 710075, China; \\ ${ }^{2}$ The Laboratory of Human Evolution, Institute of Vertebrate Paleontology and Paleoanthropology, Chinese Academy of Sciences, Beijing \\ 100044, China; \\ ${ }^{3}$ Graduate University of Chinese Academy of Sciences, Beijing 100049, China; \\ ${ }^{4}$ Nanjing Institute of Geography and Limnology, Chinese Academy of Sciences, Nanjing 210008, China
}

Received December 8, 2010; accepted January 26, 2011

\begin{abstract}
Fossilized caryopses (or grains) of foxtail millet (Setaria italica) and broomcorn millet (Panicum miliaceum) are important archaeobotanical materials for the study of early human agricultural activities. The morphology and ultrastructural characteristics of carbonized modern millets caryopses treated in a drying oven and burning in a field were investigated at different temperatures to study how fossilized millets are formed. The caryopses shrank gradually at temperatures below $200^{\circ} \mathrm{C}$, and starch granules in the endosperm retained their crystalline structure. At $250^{\circ} \mathrm{C}$ the foxtail millet caryopses expanded, whereas the broomcorn millet caryopses were greatly deformed. At this temperature, the structure of the starch granules of both millets became amorphous. At $300^{\circ} \mathrm{C}$ the caryopses partially turned to ash and became porous, and the ultrastructure of the starch granules was transformed into alveolate cavities. Fossil caryopses from the prehistoric storage cellar at the Beiniu Site retained their crystalline structure and were formed by the dehydrating effect of carbonization, indicating that water molecules were not involved in the starch crystallization. The results of a field burning experiment demonstrated that the ultrastructure of carbonized caryopses placed on the ground under the fire was amorphous. The amorphous ultrastructure of the carbonized caryopses recovered from the archaeological layers is consistent with the expected structure of caryopses that have been carbonized at $250^{\circ} \mathrm{C}$. Therefore, we suggest that the recovered caryopses were formed at about $250^{\circ} \mathrm{C}$ by baking rather than by burning in an open fire.
\end{abstract}

foxtail millet, broomcorn millet, carbonization process, ultrastructural characteristics, archaeobotany

Citation: Yang Q, Li X Q, Zhou X Y, et al. Investigation of the ultrastructural characteristics of foxtail and broomcorn millet during carbonization and its application in archaeobotany. Chinese Sci Bull, 2011, 56: 1495-1502, doi: 10.1007/s11434-011-4423-1

Sampling and identifying plant remains from different cultural layers are the initial steps in archaeobotanical studies [1]. These steps are the basis for exploring agricultural origins and development [2], understanding the agricultural activities of previous generations and their relationship with botany, and reconstructing the paleoenvironment and economic structure of early agriculture [3].

Generally speaking, plant remains can be classified into two categories: plant megafossils (e.g. seeds, fruits and

*Corresponding author (email: lixiaoqiang@ivpp.ac.cn) wood) and plant microfossils (e.g. pollen, phytoliths and starch granules) [4]. Organic materials such as seeds and fruits are liable to decompose and are not likely to be preserved in buried environments for lengthy periods. However, after being carbonized, they acquire a strong chemical resistance to decomposition and can be preserved in cultural layers without the influence of deposit conditions [5,6]. Although there are multiple interpretations of the causes of the formation of carbonized plant materials, it is generally acknowledged that most are formed through fire by baking at high temperatures [4], and some are formed by dehydration 
[7-9]. Currently, the lack of systematic studies on the causes of formation, temperature ranges and other details of the morphology and structural characteristics of plant materials during the carbonization process is a major obstacle for further research on archaeotaphonomy, morphology and ear- ly agricultural activities.

Foxtail millet (Setaria italica) and broomcorn millet (Panicum miliaceum) were major crops in the early rain-fed agricultural region of North China. They originated around 10000 a BP [10] and were widely and continuously cultivated during the Neolithic in North China, where they are systematically preserved in different cultural layers, such as the Peiligang, Cishan, Yangshao, Dawenkou, Longshan, Majiayao and Qijia cultures [4,11]. The origin, pervasion and prevalence of foxtail and broomcorn millet are of great significance in the development of the culture and civilization of East Asia.

With the widespread application of flotation in recent archaeobotanical studies, many important achievements have been made in the study of foxtail and broomcorn millets from archaeological sites [12-15]. Foxtail and broomcorn millets can be identified directly and effectively by morphology based on the external characteristics of modern grains [16-18]. Some scholars distinguish foxtail millet from broomcorn millet by analyzing the differing characteristics of the lemma and the palea with scanning electron microscopy (SEM) [19]. However, this method is always hindered due to the deformation of seeds after carbonization, which usually causes the kernels to become frangible, resulting in the loss of some important parts such as the lemma, palea, endosperm and the scar. Other scholars believe that it is feasible to improve the accuracy of identification by differentiating the internal structure of the seeds [20-22]. A study of the phytolith from each part of modern millet seeds provides a new approach to distinguish and identify prehistoric seeds [10].

However, a lack of detailed work and reliable data on the carbonization process and the formation conditions and causes (carbonization through charring or dehydration) of fossil millets affects further research on the morphological identification of fossil seeds, the storage and burial of prehistoric millet seeds, the fire activities of ancestral peoples and carbon isotope tracing used in organic geochemistry. In this paper, carbonization experiments on modern millets at different temperatures were performed to determine what changes to caryopsis morphology and ultrastructure occurred during the carbonization process and to determine the effects of different carbonization temperatures. The results were validated by field burning experiments. In addition, fossilized millet caryopses were compared with modern heated samples to determine their formation mechanism and to provide basic evidence for future studies on early agricultural activities and environmental effects.

\section{Sampling and methods}

\subsection{Sampling}

Modern samples of foxtail and broomcorn millet were collected from the Midwest Loess Plateau. Specifically, foxtail millets were sampled from Yijun County, Yan'an, Shenmu County of Shaanxi Province and Sunan County of Gansu Province. Broomtail millets were sampled from Ganquan County, Suide County of Shaanxi Province, Ejin Horo Banner and Baotou of Inner Mongolia. Fossil millet samples were obtained from the Huiduipo Site, Manan Site, Beiniu Site, Nansha Site and a prehistoric storage cellar in the Beiniu Site in Guanzhong Basin. The modern foxtail and broomcorn millets were air dried and divided into four groups according to the sites from which they were collected. Each group was randomly divided into 22 portions each composed of five kernels. The length, width and thickness of the caryopsis, and the length and width of the embryo area were measured with microscope graticules, and the average values were calculated.

\subsection{Laboratory carbonization experiments}

After measurement, 176 portions of the samples were placed into finger-shaped bottles for carbonization. The millet kernels were placed equidistantly on the wire frame of a drying oven and heated to $50^{\circ} \mathrm{C}$ or $100^{\circ} \mathrm{C}$ for $3 \mathrm{~h}$ and to $200^{\circ} \mathrm{C}$, $250^{\circ} \mathrm{C}$, or $300^{\circ} \mathrm{C}$ for $0.5,1,2,4$ or $8 \mathrm{~h}$ to obtain kernels that were carbonized under different charring temperatures.

\subsection{Morphological characteristics of the manually carbonized samples}

After carbonization, all of the carbonized grains were observed under a binocular stereomicroscope. The length, width and thickness of the caryopsis as well as the length and width of the embryo area were measured using microscope graticules, and the average values were calculated.

\subsection{Field carbonization experiments}

Dry wood and branches were burned to carbonize modern foxtail and broomcorn millet samples for approximately 45 min in a pit of $15 \mathrm{~cm}$ depth dug into the ground. Four different methods were used to char the samples: (1) samples were buried in a hole $3-5 \mathrm{~cm}$ deep covered with soil at the bottom of the fire stack; (2) samples were placed on the ground at the bottom of the fire stack; (3) samples were distributed around the fire stack; and (4) samples were placed in the center of the fire stack.

\subsection{Observation of starch ultrastructure in the endosperm by SEM}

Observation of cross-sections of foxtail and broomcorn 
millet caryopses showed that they were composed of three parts, namely the seed coat, embryo and endosperm [23]. Starch is a natural crystalline polymer and is the main constituent of the endosperm of mature seeds in herbaceous plants $[24,25]$. Starch granules are clustered in an orderly manner with amylase and amylopectin and in structure consists of a crystalline section alternating with a non-crystalline section [26]. Observation of the size, shape, configuration and arrangement of the starch granules using an SEM is fundamental for analysis of the ultrastructural characteristics of seeds heated at different temperatures.

The following samples were selected for examination of their ultrastructural characteristics: (1) modern millets without treatment, (2) millets subjected to laboratory carbonization, (3) fossil millets from archaeological layers from each site and the prehistoric storage cellar at the Beiniu Site, and (4) millets subjected to field carbonization. A rupture in the central part of the kernel was made by spinning and striking the kernel with a blade while clamped, and then it was chipped along the breakpoint with the blade. The fracture surface of the samples was observed and photographed with a Zeiss Evo Ma10 SEM (Carl Zeiss SMT Ltd, Cambridge, England) after being affixed to sample stages using electroconductive double-sided tape.

\section{Results}

\subsection{Morphological changes in the laboratory carbonized seeds}

Vertical step of the changes in morphological features of foxtail and broomcorn millets with heating are presented in Figure 1(a), (b). The endosperm and embryo area of the caryopsis heated at $50^{\circ} \mathrm{C}$ or $100^{\circ} \mathrm{C}$ for $3 \mathrm{~h}$ showed no evidence of charring. The embryo area of the caryopsis heated at $150^{\circ} \mathrm{C}$ was obviously carbonized, but no changes were seen in the seed coat except that the color slightly deepened with increasing heating time, finally turning brown after heating for $8 \mathrm{~h}$. There were no significant changes to each morphological feature of the caryopsis, except that the embryo area width was distinctly shortened $(<-5 \%)$, at temperatures below $200^{\circ} \mathrm{C}$. The caryopsis tended to shrink gradually with rising temperature and increasing heating duration. For foxtail millet, in particular, the caryopsis length increased by $1.80 \%$ after heating at $100^{\circ} \mathrm{C}$ for $3 \mathrm{~h}$ but was reduced by $3.10 \%$ at $200^{\circ} \mathrm{C}$ for $1 \mathrm{~h}$. The caryopsis width was reduced by $0.28 \%$ to $3.79 \%$ and the caryopsis thickness was reduced by $1.83 \%$ to $7.00 \%$. For broomcorn millet, the caryopsis length was reduced by $1.10 \%$ to $2.66 \%$, and the caryopsis width was reduced by $0.80 \%$ to $1.84 \%$.

The seed coats of kernels heated at $200^{\circ} \mathrm{C}$ for only $0.5 \mathrm{~h}$ were charred to black, but their shape did not change significantly over time. The data showed that all of the kernel features tended to shrink to some extent, except for a slight increase in caryopsis thickness (Table 1), which, in turn, changed the ratios of several important characteristics of the kernel. The caryopsis length:width ratios showed no significant change for foxtail and broomcorn millet, whereas the embryo area length:width ratios tended to increase for foxtail millet but decreased for broomcorn millet. The ratios of caryopsis length to embryo area length increased for broomcorn millet, whereas the ratio of caryopsis length to embryo area length showed no significant change trends for foxtail millet.

At $250^{\circ} \mathrm{C}$, kernels heated for only $0.5 \mathrm{~h}$ were very charred and showed similar shape characteristics for different charring times. The kernels became substantially deformed and exhibited bulging due to the high temperature. A lipid that exuded from the kernels while they were being charred coagulated when cooled, and the kernels adhered together owing to the lipid. The morphological features changed significantly in foxtail millet. The length, width and thickness of the caryopsis and embryo area width all increased notably, but the embryo area length decreased significantly. The broomcorn millets were too badly deformed to be measured after heating at $250^{\circ} \mathrm{C}$.

The carbonized grains were deformed so badly at $300^{\circ} \mathrm{C}$ that both the foxtail and broomcorn millets became partially ashen while exuding lipids and exhibited bursting. Alveolate cavities also occurred, making it impossible to measure the morphological features of both millets.

\subsection{Ultrastructural characteristics of the modern and fossilized millets}

Observation of the shape and size of starch granules in different parts of the modern millet endosperms using an SEM showed that the arrangement of the starch granules in foxtail millet had a regular pattern. Starch granules are characterized by their crystalline structure. The endosperm contained both 'hard' and 'soft' areas. The 'hard' area on the fringe of the endosperm had a tightly packed cellular arrangement with no air spaces and the starch granules are polygonal shapes (Figure 2(a)). In these cells very small starch granules were covered by a thin layer of protein. The proteins left large indentations on the margins of the starch granules. In contrast, the 'soft' endosperm area contained relatively large air spaces and the cells were loosely packed. These cells contained spherical starch granules (Figure 2(b)), and protein bodies appeared to be absent [27]. Cavities were clearly evident in many fractured starch granules (Figure 2(c)). For broomcorn millet, the shape and size of the starch layers and constituents varied in different parts of the endosperm. Starch granules and protein were the major constituents of the endosperm cells in both the 'hard' and 'soft' areas. Protein bodies were embedded in the protein matrix that covered the starch granules [23]. The shape of the starch granules was predominantly polygonal and supplemented by spherical granules (Figure 3(a),(b)). The granules were 

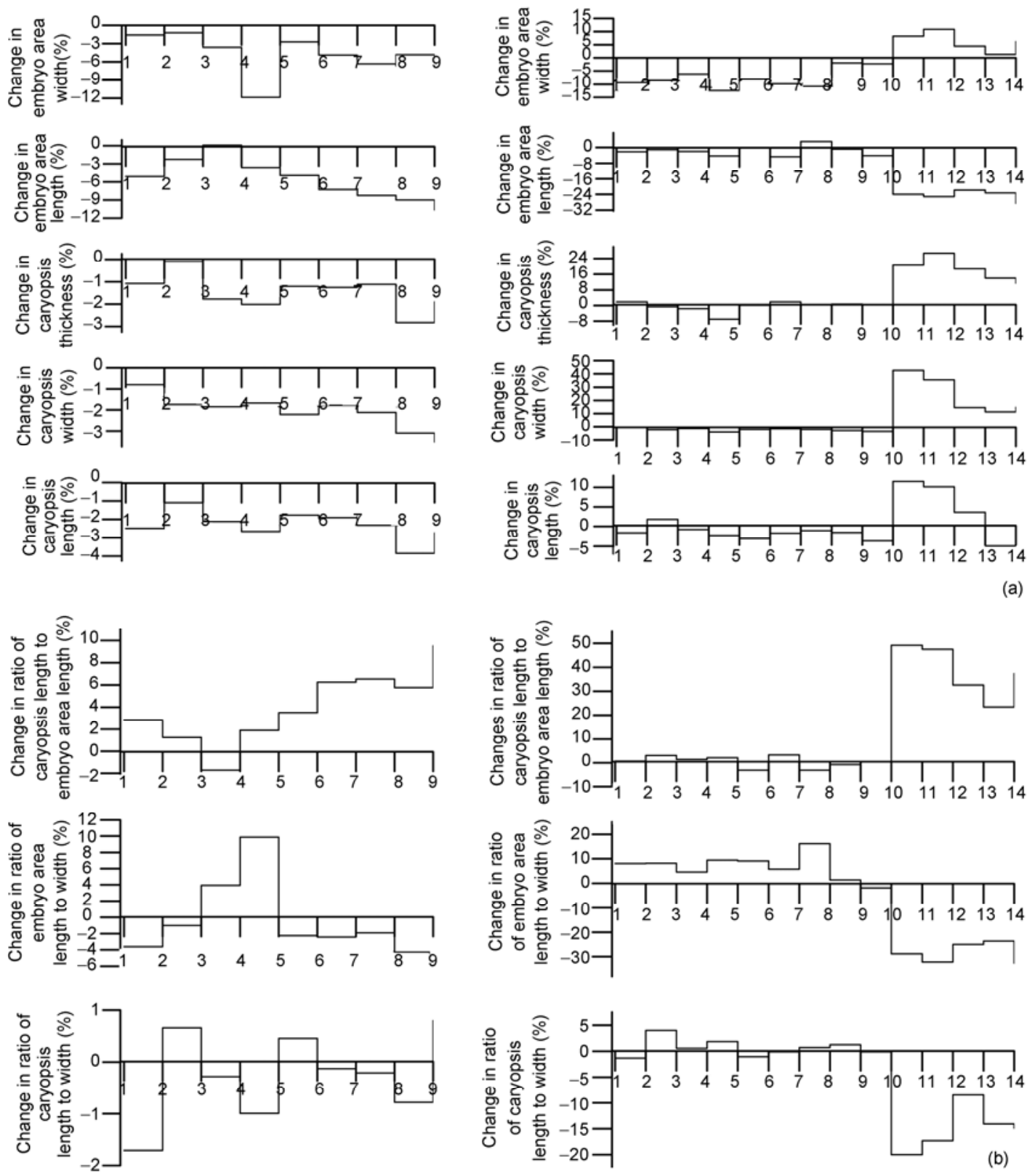

Figure 1 Changes in morphological characteristics (a) and ratios of specific morphological characteristics (b) of caryopses of broomcorn millet (left) and foxtail millet (right) with increasing temperature. Numbers $1-14$ on the $x$-axis represent different heating conditions as follows: 1 , Heating at $50^{\circ} \mathrm{C}$ for $3 \mathrm{~h} ; 2$, heating at $100^{\circ} \mathrm{C}$ for $3 \mathrm{~h} ; 3$, heating at $150^{\circ} \mathrm{C}$ for $2 \mathrm{~h} ; 4$, heating at $150^{\circ} \mathrm{C}$ for $8 \mathrm{~h} ; 5$, heating at $200^{\circ} \mathrm{C}$ for $0.5 \mathrm{~h} ; 6$, heating at $200^{\circ} \mathrm{C}$ for $1 \mathrm{~h} ; 7$, heating at $200^{\circ} \mathrm{C}$ for $2 \mathrm{~h} ; 8$, heating at $200^{\circ} \mathrm{C}$ for $4 \mathrm{~h} ; 9$, heating at $200^{\circ} \mathrm{C}$ for $8 \mathrm{~h} ; 10$, heating at $250^{\circ} \mathrm{C}$ for $0.5 \mathrm{~h} ; 11$, heating at $250^{\circ} \mathrm{C}$ for $1 \mathrm{~h} ; 12$, heating at $250^{\circ} \mathrm{C}$ for 2 $\mathrm{h} ; 13$, heating at $250^{\circ} \mathrm{C}$ for $4 \mathrm{~h} ; 14$, heating at $250^{\circ} \mathrm{C}$ for $8 \mathrm{~h}$.

somewhat smaller than those of foxtail millet, which agrees with the results of previous research [28]. Cavities were also clearly evident in the center of the starch granules (Figure 3(c)).

The SEM analysis of cross-sections of laboratory carbonized samples showed that the ultrastructural characteristics of both foxtail and broomcorn millet caryopses varied significantly with increasing temperature but remained consistent at the same temperature even if the heating duration increased. Millet samples heated to 50,100 or $150^{\circ} \mathrm{C}$ retained strong resistance to charring (Figures 2(d), 3(d)), similar to that of intact kernels. At temperatures up to $200^{\circ} \mathrm{C}$, the submicroscopic cracks appeared in the endosperm (Figure 2(f)) but no structural changes occurred in the starch granules (Figures 2(e), 3(e)). At $250^{\circ} \mathrm{C}$, starch granules were destroyed and became indistinguishable, and their structure became amorphous in foxtail millet (Figure $2(\mathrm{~g}))$. For broomcorn millet, the central part of the endosperm became amorphous (Figure 3(f)), but the peripheral area showed no changes after heating at $250^{\circ} \mathrm{C}$ for $30 \mathrm{~min}$. After heating at $250^{\circ} \mathrm{C}$ for $8 \mathrm{~h}$, the structure in the peripheral part 
Table 1 Changes in morphological characteristics of foxtail and broomcorn millet caryopses heated at $200^{\circ} \mathrm{C}^{\text {a) }}$

\begin{tabular}{|c|c|c|c|c|c|c|c|c|c|}
\hline \multirow{2}{*}{ Species } & \multirow{2}{*}{ Heating duration (h) } & \multicolumn{4}{|c|}{ Change in caryopsis (\%) } & \multicolumn{3}{|c|}{ Change in embryo area $(\%)$} & \multirow{2}{*}{$\begin{array}{c}\text { Change in ratio of caryopsis length } \\
\text { to embryo area length }(\%)\end{array}$} \\
\hline & & $\mathrm{L}$ & $\mathrm{W}$ & $\mathrm{T}$ & $\mathrm{L} / \mathrm{W}$ & $\mathrm{L}$ & $\mathrm{W}$ & $\mathrm{L} / \mathrm{W}$ & \\
\hline \multirow{5}{*}{ Foxtail millet } & 0.5 & -3.10 & -2.03 & 0.21 & -1.09 & 0.06 & -8.07 & 9.07 & -3.07 \\
\hline & 1 & -1.69 & -1.53 & 1.84 & -0.12 & -4.73 & -9.82 & 5.79 & 3.29 \\
\hline & 2 & -1.09 & -1.91 & 0.55 & 0.68 & 3.09 & -10.85 & 16.17 & -3.10 \\
\hline & 4 & -1.60 & -2.81 & 0.78 & 1.25 & -0.78 & -1.96 & 1.36 & -0.79 \\
\hline & 8 & -3.65 & -3.50 & 0.54 & -0.15 & -4.13 & -2.26 & -1.87 & 0.55 \\
\hline \multirow{4}{*}{ Broomcorn millet } & 1 & -1.90 & -1.78 & -1.26 & -0.13 & -7.26 & -4.86 & -2.44 & 6.25 \\
\hline & 2 & -2.32 & -2.11 & -1.12 & -0.21 & -8.28 & -6.35 & -1.89 & 6.53 \\
\hline & 4 & -3.85 & -3.09 & -2.82 & -0.78 & -9.01 & -4.84 & -4.29 & 5.75 \\
\hline & 8 & -2.73 & -3.51 & -1.90 & 0.80 & -10.65 & -5.35 & -5.55 & 9.50 \\
\hline
\end{tabular}

a) L, W and T are length, width and thickness, respectively. Data represent the mean percentage increase or decrease after treatment compared with non-treated caryopses $(n=5)$.
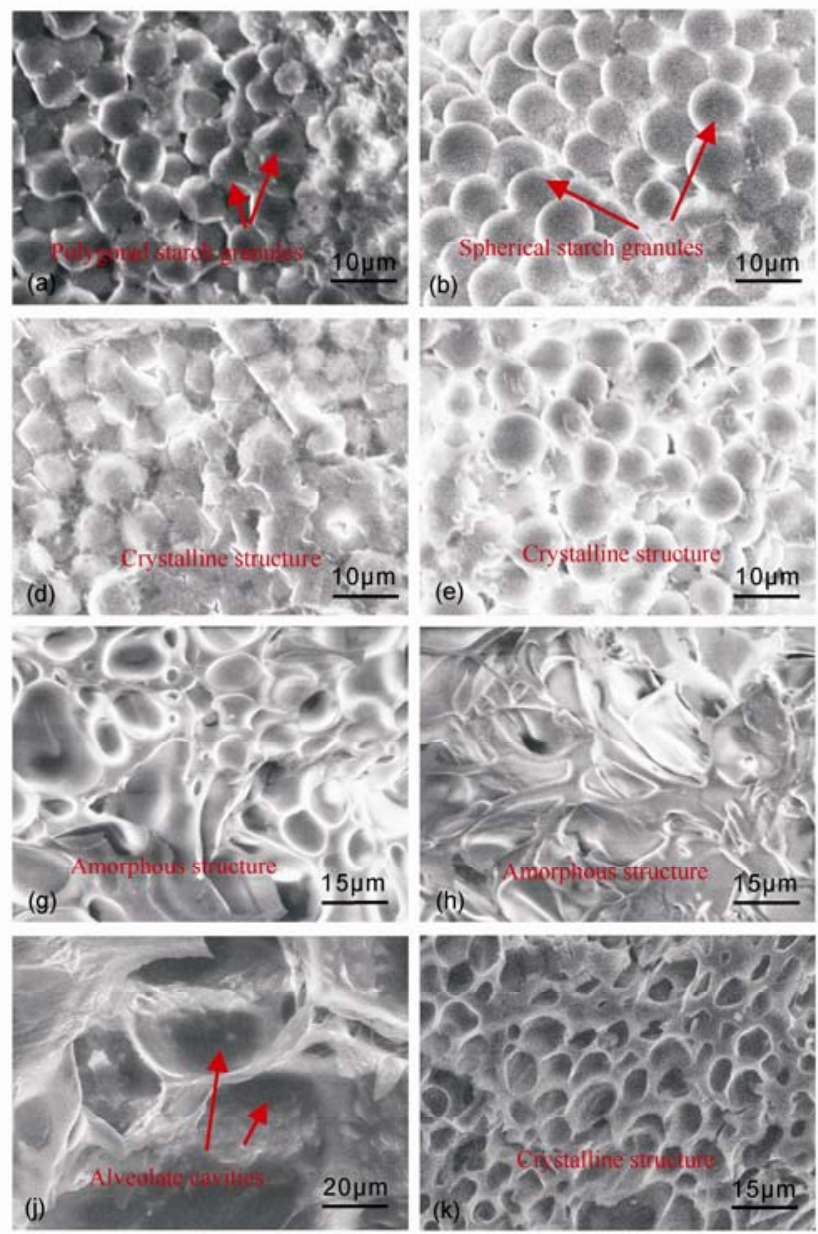
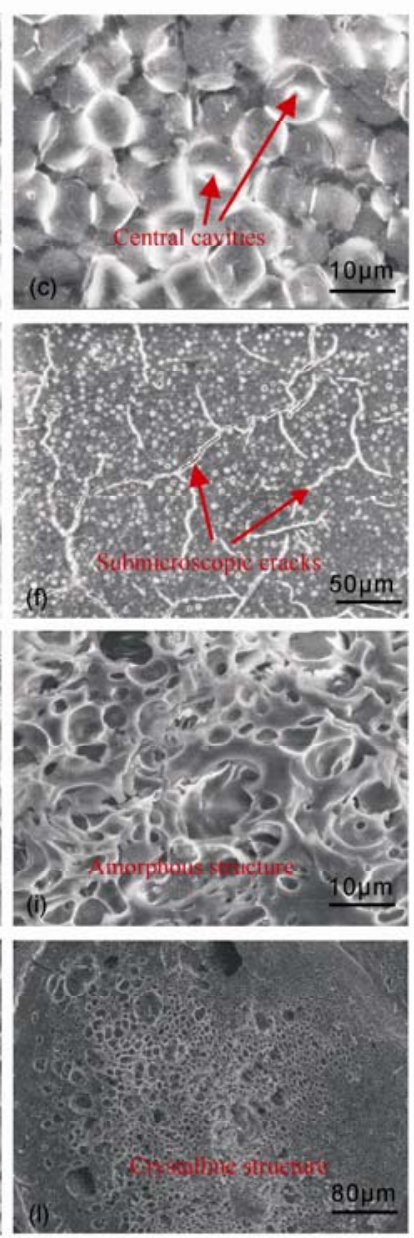

Figure 2 Scanning electron micrographs of the cross-sections of foxtail millet caryopses. (a)-(c) Modern caryopses without any treatment; (d) caryopsis heated at $150^{\circ} \mathrm{C}$; (e)-(f) caryopsis heated at $200^{\circ} \mathrm{C}$; (g) caryopsis heated at $250^{\circ} \mathrm{C}$; (h) caryopsis heated on the ground at the bottom of the fire stack in the field carbonization experiment; (i) caryopsis obtained from the Nansha Site culture layer; (j) caryopsis heated at $300^{\circ} \mathrm{C}$; (k)-(l) caryopsis extracted from the archaeological pit at the Beiniu Site.

of the endosperm was amorphous (Figure 3(g)). Following heating at $300^{\circ} \mathrm{C}$, the cells became alveolate cavities and no starch granules were observed (Figures 2(j), 3(j)).

Examination by SEM of the cross-sections of the fossil seeds showed that kernels from the Yangshao culture layer had an obviously amorphous structure (Figures 2(i),3(j)). However, kernels from the prehistoric storage cellar at the Beiniu Site retained their crystalline structure in the absence of starch, and the cavities were arranged tightly in the endosperm (Figures $2(\mathrm{k}), 3(\mathrm{k})$ ). In addition, the cavities gradually 

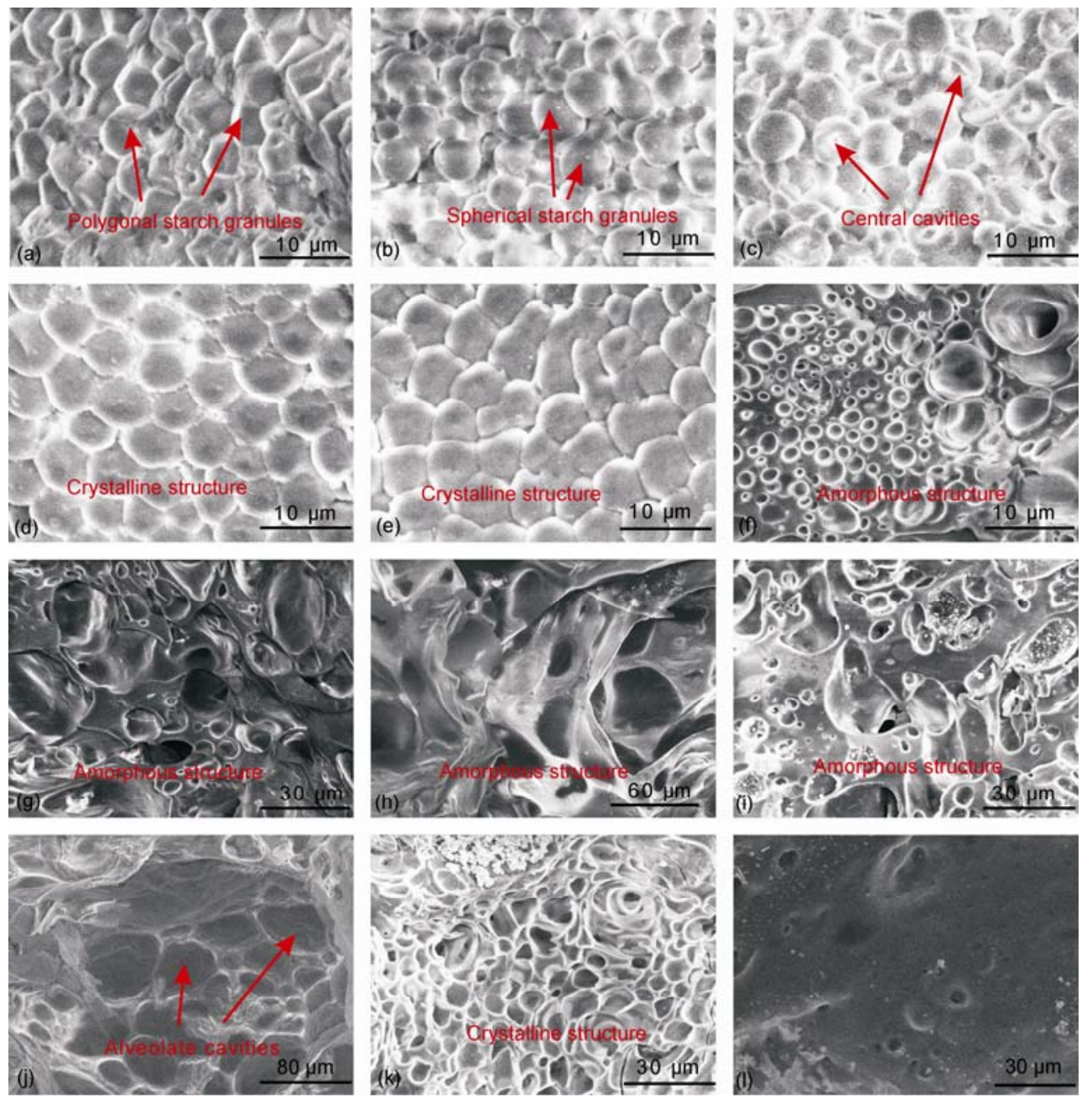

Figure 3 Scanning electron micrographs of the cross-sections of broomcorn millet caryopses. (a)-(c) Modern caryopses without manual handling; (d) caryopsis heated at $150^{\circ} \mathrm{C}$; (e) caryopsis heated at $200^{\circ} \mathrm{C}$; (f) caryopsis heated at $250^{\circ} \mathrm{C}$ for $0.5 \mathrm{~h}$; (g) caryopsis heated at $250^{\circ} \mathrm{C}$ for $8 \mathrm{~h}$; (h) caryopsis heated on the ground at the bottom of the fire stack in the field carbonization experiment; (i) caryopsis obtained from the Manan Site culture layer; (j) caryopsis heated at $300^{\circ} \mathrm{C}$; (k) caryopsis obtained from the archaeological pit at the Beiniu Site; (1) caryopsis distributed around the fire in the field carbonization experiment.

increased in size from the periphery to the central part of the endosperm in foxtail millet (Figure 2(1))

\subsection{Carbonization of caryopses in the field}

No sings for carbonization was observed in samples treated with the soil burial method, whereas different degrees of charring occurred in samples distributed around or within the fire stack. The foxtail and broomcorn millet samples placed on the ground at the bottom of the fire stack were carbonized to black, but most of the samples maintained a perfect kernel structure with little change in morphology. However, a few samples burst and oil oozed through the ruptures causing deformation. The samples distributed around the fire stack underwent a greater degree of carbonization. Most of these samples burst and the organic matter was incinerated; therefore, the morphology of the samples was imperfect. The samples placed in the center of the fire stack were severely charred and most were burnt to ash.

SEM examination of the ultrastructure of samples treated with each burning method revealed that samples from the soil burial method retained their freshness. The ultrastructure of samples placed on the ground at the bottom of the fire stack was amorphous (Figures 2(h), 3(h)), which was consistent with the structure of samples from the laboratory carbonization experiments and the fossil samples from the cultural layers. The starch granules of the samples distributed around the fire stack, with crystalline or amorphous structure absenting, were very different in ultrastructure to the samples carbonized under other conditions.

\section{Discussion and conclusion}

There are two main types of carbonized plant remains. One is formed through desiccation and carbonization under special 
burial conditions without high temperature. Historically, it was important to preserve cereals in a safe place after harvesting, and the most pervasive method was to store them in a root cellar [29]. A large quantity of fossil millets was found in the prehistoric storage cellar of the Beiniu Site in Guanzhong Basin. Millet kernels from this site retained an intact shape without any distortion in kernel shape or crystalline structure in the starch granules. The evidence indicates that water molecules were not involved in starch crystallization for these samples [30]. Moreover, the cavity size of the fossil caryopses from the archaeological cellar tended to increase gradually from the periphery to the central part of the seed. This characteristic is consistent with that of the starch granule size of modern caryopses, which is small at the periphery and larger in the center. Therefore, fossilized plants from special burial conditions, such as cellars, can be regarded as a product of dehydration without the effects of high temperature.

The other is seed remains obtained from cultural layers. It is generally acknowledged that they were formed through the high temperatures of fires because they were usually accompanied with charred wood or fossilized charcoal $[4,16]$. Therefore, the formation methods and origins of carbonized plant remains have always attracted a great deal of attention in the field of archaeobotany, and manual carbonization experiments became the main method for exploring solutions to these problems.

Manual carbonization is a xerothermic treatment that is performed by placing seeds in a dry and hot condition for a long period of time. In the present study, comparison of millet samples heated at different temperatures for increasing time periods indicated that the morphological features of caryopses change with differing heating temperatures and time periods. The severity of the carbonization of caryopses depended on the temperature rather than the duration of heating. That is, the duration of heating from 0.5 to $8 \mathrm{~h}$ had little effect on the extent of charring of samples at the same temperature. The caryopsis tended to shrink gradually at temperatures below $200^{\circ} \mathrm{C}$ but swelled at $250^{\circ} \mathrm{C}$ for foxtail millet and even ruptured in broomcorn millet. The kernels were covered with exudations and became so substantially deformed that their morphological characteristics could not be measured. At $300^{\circ} \mathrm{C}$, the kernels became partially ashen with alveolate cavities. This might be caused by the release of water molecules from cells induced by heating, which led to dehydration and shrinkage; however, the temperature was not high enough to change the structure of starch granules at temperatures $\leqslant 200^{\circ} \mathrm{C}$. However, a rapid loss of water and the carbonization of organic matter resulted in ultrastructural changes in the endosperm at temperatures of $250^{\circ} \mathrm{C}$ and $300^{\circ} \mathrm{C}$. Therefore, temperature, rather than heating duration, was the critical factor affecting the degree of carbonization of the caryopses.

Comparison of the data for the two millets under different heating conditions showed that the kernel shape did not change much at temperatures lower than $200^{\circ} \mathrm{C}$; at $200^{\circ} \mathrm{C}$, the kernel shape was recognizable even though the kernel size changed significantly. At $250^{\circ} \mathrm{C}$, the caryopsis shape changed substantially, especially for broomcorn millet, and it was difficult to identify the foxtail and broomcorn millets by features of the caryopsis and embryo area due to the exudations that covered the kernel bodies. At $300^{\circ} \mathrm{C}$, the shape of the kernels changed beyond all recognition such that the two millets could not be identified.

The ultrastructural characteristics of the grains carbonized in the laboratory experiments showed that the starch granules in the endosperm retained their crystalline structure at $150^{\circ} \mathrm{C}$. At $200^{\circ} \mathrm{C}$, submicroscopic cracks appeared in the endosperm caused by water evaporation. At $250^{\circ} \mathrm{C}$, the amorphous structure of the starch granules, which could barely be recognized in the endosperm, was caused by the high temperature. In particular, with heating the starch granules tended to expand and rupture. As a consequence, the starch was gelatinized and the crystalline structure was destroyed. The central area of the endosperm was weakly organized and always the first to undergo disruption induced by heating [31], which was demonstrated by the fact that ultrastructural changes occurred first in the central endosperm cells in broomcorn millet. At $300^{\circ} \mathrm{C}$, the high temperature caused the starch granules to be carbonized fully to carbon and other refractory remains, making the starch granules unrecognizable and transforming their structure to alveolate cavities. These results clearly demonstrated that the ultrastructure of the seeds changed significantly with increasing temperature, but the heating duration had no notable effect. This conclusion is consistent with the analysis of morphological characteristics discussed above.

The amorphous structure of the fossil caryopses from the cultural layers of the Huiduipo Site, Manan Site, Beiniu Site and Nansha Site in Guanzhong Basin was caused by progressive heating to a certain temperature. During the drying and desiccation process, water molecules from the caryopsis first involved in crystallization, but then the crystalline structure was lost due to the high temperature. Finally, the ultrastructure became amorphous [31]. The ultrastructural characteristics of these fossil caryopses and the modern samples heated at $250^{\circ} \mathrm{C}$ were comparable; in both the ultrastructure was amorphous. Therefore, the temperatures used in manual carbonization experiments are an important factor for investigating the formation of carbonized seed remains.

A comparison of the ultrastructural characteristics of foxtail and broomcorn millet samples treated in the field carbonization experiment suggested that the samples treated with the soil burial method were not affected by fire, and no evidence for carbonization was observed. However, samples distributed around or within the fire were significantly affected by fire and were charred to varying degrees. This can be explained by the differing temperatures in different parts of the fire stack. The samples placed at the bottom of the fire stack showed the same ultrastructure as the samples heated at $250^{\circ} \mathrm{C}$ in the manual carbonization experiments. This result indicates that the amorphous ultrastructure of a 
seed could only develop under certain conditions (e.g. heating by baking). Meanwhile, the marked differences in the ultrastructural characteristics of samples burned with fire and those from archaeological sites suggest that the carbonized seed remains did not undergo direct burning by fire.

In conclusion, analysis of the ultrastructural characteristics of fossil, modern, manually carbonized and fieldcharred caryopses of foxtail and broomcorn millet revealed that under certain conditions their characteristics were comparable and provided a basis for the determination of carbonized conditions. Combined with their morphological characteristics, a further analysis of the ultrastructural characteristics of manually carbonized and fossil caryopses from cultural layers revealed that temperatures below $200^{\circ} \mathrm{C}$ do not provide enough heat to destroy the crystalline structure of starch granules. At $250^{\circ} \mathrm{C}$, the structure of the starch granules became amorphous. At $300^{\circ} \mathrm{C}$, the kernels partially turned to ash and became porous. The amorphous structure of carbonized caryopses recovered from archaeological layers was consistent with the expected structure of caryopses carbonized at $250^{\circ} \mathrm{C}$. The structure maintained the kernel's shape and precluded their decomposition in a buried environment. Therefore, supported by the results of our field burning experiments, we suggest that the fossil caryopses from the cultural layers were formed at about $250^{\circ} \mathrm{C}$ by baking rather than by direct burning by fire.

The authors thank Hu Songmei, Archaeology Institute of Shaanxi, for his suggestions and help in the sampling and investigation of the fossil caryopses. We are also grateful to the editor and the anonymous reviewers for their constructive comments and suggestions for this manuscript. This work was supported by the National Basic Research Program of China (2010CB950204) and the Knowledge Innovation Program of the Chinese Academy of Sciences (KZCX2-YW-Q1-03).

1 Renfrew C, Bahn P. Archaeobotany: Theories, Methods and Practice (in Chinese). Beijing: Cultural Relics Publishing House, 2004. 240-248

2 Li X Q, Zhou X Y, Zhang H B, et al. The record of cultivated rice from archaeobiological evidence in northwestern China 5000 years ago. Chinese Sci Bull, 2007, 52: 1372-1378

3 Zhao Z J. Disciplinary position and research content of paleoethnobotany (in Chinese). Archaeology, 2001, 7: 55-61

4 Liu C J, Jin G Y, Kong Z C. Archaeobotany-Research on Seeds and Fruits (in Chinese). Beijing: Science Press, 2008. 11-14, 44-51, 160-171

5 Zhao Z J. The plant archaeology study on the origin of agriculture and civilization (in Chinese). Manag Rev Soc Sci, 2005, 2: 82-91

6 Zhao Z J. Archaeobotany and its recent advances (in Chinese). Archaeol, 2005, 7: 42-49

7 Liu C J, Li Y C. Identification of the objects floatation-selected from the soil samples collected to the Liao Tomb in Xuanhua (in Chinese). In: Hebei Provincial Cultural Relics Archaeological Research Institute, ed. The Liao Tomb in Xuanhua, Vol 1. Beijing: Cultural Relics Publishing House, 2001. 347-351

8 Jiang $\mathrm{H}$ E, Li X, Zhao Y X, et al. A new insight into Cannabis sativa (Cannabaceae) utilization from 2500-year-old Yanghai Tombs, Xinjiang, China. J Ethnophar, 2006, 108: 414-422

9 Jiang H E, Li X, Liu C J, et al. Fruits of Lithospermum officinale
L.(Boraginaceae) used as an early plant decoration (2500 a BP) in Xinjiang, China. J Archaeol Sci, 2007, 2: 167-170

10 Lü H Y, Zhang J P, Liu K-B, et al. Earliest domestication of common millet (Panicum miliaceum) in East Asia extended to 10000 years ago. Proc Natl Acad Sci USA, 2009, 18: 7367-7372

11 An Z M. Prehistoric agriculture in China (in Chinese). Act Archaeol Sin, 1988, 4: 369-381

12 Kong Z C, Liu C J, He D L. Discovery of plant remains at the Zhuangxili site, Tengzhou city, Shandong Province and their significance in environmental archaeology (in Chinese). Archaeology, 1999, 7: 59-62

13 Kong Z C, Liu C J, Zhang J Z. Discovery of plant remains in the Neolithic site at the Bancun site, Mianchi county, Henan Province and their significance in human environment (in Chinese). Acta Anthropol Sin, 1999, 4: 291-295

14 Crawford C, Zhao Z J, Luan F S, et al. A preliminary analysis of the Longshan culture plant remains from the Liangchengzhen Site in Rizhao city, Shandong (in Chinese). Archaeol, 2004, 9: 73-80

15 Li X Q, Zhou X Y, Zhou J, et al. The earliest archaeobiological evidence of the broadening agriculture in China recorded at Xishanping site in Gansu Province. Sci China Ser D-Earth Sci, 2007, 11: 17071714

16 Liu C J, Kong Z C. Morphological comparison of foxtail millet and broomcorn millet and its significance in archaeological identification (in Chinese). Archaeology, 2004, 8: 76-83

17 Zhao Z J, He N. Identification and analysis of the objects floatation-selected from the soil samples collected to the Taosi Site in Xiangfen (in Chinese). Archaeology, 2006, 5: 77-86

18 Yang X Y, Liu C J, Zhang J P, et al. Plant crop remains from the outer burial pit of the Han Yangling Mausoleum and their significance to Early Western Han agriculture. Chinese Sci Bull, 2009, 54: 1738-1743

19 Matsutani A. Identification of Italian Millet from Esashika Site by means of scanning electron microscope. J Anthrop Soc Nippon, 1986, 94: $111-118$

20 Ji D X. Research history and methods of archaeobotany (in Chinese). Agr Archaeol, 2008, 4: 17-28

21 Liu H H, Zhou H Y, Zhang W X. Preliminary observation on fine structure of starch grains in rice endosperm (in Chinese). J Chin Electron Microsc Soc, 2001, 20: 185-188

22 Yang X Y, Lu H Y, Xia Z K. Analysis of starch granules in plants and its application in archaeology (in Chinese). Archaeol Cultural Relics, 2006, 87-91

23 Chai Y. Broomcorn Millet (in Chinese). Beijing: Chinese Agriculture Press, 1999. 44-45

24 Li H Y. Morphology and anatomy of Gramineae (in Chinese). Shanghai: Shanghai Scientific and Technical Publishers, 1979. 380-381

25 Zhou Z Q, Zhu X T, Wang W J, et al. Varieties with different kernel types by scanning electron microscope (in Chinese). J Chin Electron Microsc Soc, 2001, 3: 178-184

26 Yang J F, Luo Z G, Luo F X. Research progress of the crystalline structure of starch (in Chinese). Sci Technol Food Ind, 2007, 28: 240-243

27 Badi S M, Hoseney R C, Casad A J. Pearl millet. I. Characterization by SEM, amino acid analysis, lipid composition, and prolamine solubility. Cereal Chem, 1975, 4: 478-487

28 Ge W, Liu L, Jin Z Y. Morphological analyses on starch granules of five grass species and their significance for archaeology (in Chinese). Quat Sci, 2010, 2: 377-384

29 Kong Z C, Liu C J, Zhang J Z, et al. Plant relics in the archaeological sites of China and the virgin agriculture (in Chinese). Cult Relics Central Chin, 2003, 2: 4-13

30 Hizukuri S. Starch Science Handbook (in Japanese). Tokyo: Asakura Publishing Co. Ltd., 1977. 31-32

31 Huang Q, Lou F X, Yang L S. Progress of research on the starch granules (in Chinese). Polymer Mater Sci Eng, 2004, 20: 19-23

Open Access This article is distributed under the terms of the Creative Commons Attribution License which permits any use, distribution, and reproduction in any medium, provided the original author(s) and source are credited. 